\title{
IDENTIFIKASI INDIKATOR PENILAIAN KINERJA ANGGOTA DEWAN PERWAKILAN MAHASISWA UNIVERSITAS TELKOM
}

\section{IDENTIFICATION OF MEMBERS PERFORMANCE ASSESSMENT INDICATORS OF TELKOM UNIVERSITY STUDENTS REPRESENTATIVE COUNCIL}

\author{
Mochammad Faizal \\ Prodi S2 Manajemen, Fakultas Ekonomi dan Bisnis \\ Universitas Telkom, Bandung, Indonesia \\ hai@mf-chan.com
}

\begin{abstract}
Abstrak
DPM Kema Tel-U merupakan sebuah lembaga legislatif mahasiswa di Universitas Telkom yang diresmikan pada tahun 2014. Menyadari pentingnya kehadiran manajemen sumber daya manusia dalam sebuah organisasi, DPM Kema Tel-U memiliki masalah yaitu belum memiliki standar untuk penilaian kinerja anggota. Hal ini menyebabkan aktivitas pengembangan sumber daya manusia tidak dapat berjalan optimal. Penelitian ini dilakukan dengan tujuan untuk mengetahui variabel penilaian kinerja pada DPM Kema Tel-U. Metode penelitian yang digunakan adalah kualitatif, dengan jenis data yang dibutuhkan adalah data primer dan data sekunder. Data primer dikumpulkan melalui focus group discussion dan wawancara mendalam terhadap DPM Kema Tel-U yang akan melibatkan 28 responden, dan data sekunder dikumpulkan melalui studi literatur. Hasil dari penelitian ini adalah untuk mengidentifikasi indikator penilaian kinerja untuk memperbaiki kualitas anggota dan lingkungan kerja Dewan Perwakilan Mahasiswa di Universitas Telkom, maupun perguruan tinggi lainnya.
\end{abstract}

Kata kunci : dewan perwakilan mahasiswa, kinerja, manajemen sumber daya manusia, organisasi mahasiswa

\begin{abstract}
DPM Kema Tel-U is a student legislative body at Telkom University which was inaugurated in 2014. Recognizing the importance of the presence of human resource management in an organization, DPM Kema Tel-U has a problem of not having standards for evaluating their member's performance. This causes the activity of developing human resources cannot run optimally. This research was conducted to find out the performance assessment variables at DPM Kema Tel-U. The research method used is qualitative, with the type of data needed are primary data and secondary data. Primary data was collected through focus group discussions and in-depth interviews with DPM Kema Tel-U which involved 28 respondents, and secondary data was collected through literature studies. The results of this study were to identify performance assessment indicators to improve the quality of members and the working environment of Student Representatives at Telkom University, as well as other universities.
\end{abstract}

Keywords : human resource management, performance, student organization, student representative board

\section{Pendahuluan}

Perguruan tinggi tidak terlepas dari berbagai kegiatan mahasiswa yang berorientasi pada Tri Dharma Perguruan Tinggi, yakni pendidikan, penelitian, dan pengabdian pada masyarakat. Tri Dharma tersebut tertuang pada berbagai kegiatan mahasiswa, seperti halnya dalam berorganisasi. Universitas Telkom yang memiliki visi untuk menjadi universitas berkelas dunia, telah memiliki beberapa macam organisasi mahasiswa dalam rangka menyalurkan dan mengembangkan potensi diri mahasiswanya. Organisasi-organisasi tersebut di antaranya adalah Dewan Perwakilan Mahasiswa, Badan Eksekutif Mahasiswa, Unit Kegiatan Mahasiswa, Unit Kerohanian Mahasiswa, dan Himpunan Mahasiswa. Kelima macam organisasi tersebut bergerak pada berbagai bidang dan tingkatan yang berbeda, baik dalam lingkup program studi, fakultas, maupun universitas.

Semenjak diresmikannya Universitas Telkom, pada tahun 2014 telah dibentuk Dewan Perwakilan Mahasiswa Keluarga Mahasiswa Telkom University atau biasa disebut DPM Kema Tel-U, sebagai lembaga legislatif mahasiswa tertinggi yang beranggotakan mahasiswa dari tujuh fakultas yang ada pada Universitas Telkom. DPM 
Kema Tel-U memiliki tugas dalam melaksanakan dan mengawasi Anggaran Dasar, Anggaran Rumah Tangga, Garis Besar Haluan Organisasi, serta Rekomendasi Kerja Kema Tel-U ke dalam berbagai program kerja DPM Kema Tel-U, untuk menjalankan fungsi pengawasan, legislasi, aspirasi, serta anggaran yang dimilikinya.

Pada tahun kepengurusan 2017-2018 atau tahun keempat DPM Kema Tel-U berjalan, DPM Kema Tel-U memiliki Badan Urusan Rumah Tangga atau BURT yang bertanggung-jawab sebagai unit yang mengelola sumber daya pada organisasi. BURT memiliki beberapa kegiatan, salah satunya adalah pengadaan program kaderisasi untuk menghasilkan generasi penerus DPM Kema Tel-U pada periode berikutnya. Hal ini menjadi sebuah indikasi bahwa DPM Kema Tel-U telah menerapkan manajemen sumber daya manusia, dan peduli akan keberlangsungan dari organisasi itu sendiri.

Tabel 1. Tabel perbandingan berdasarkan teori dan implementasi DPM Kema Tel-U

\begin{tabular}{|l|l|}
\hline \multicolumn{1}{|c|}{ Teori Fungsi Manajemen SDM } & \multicolumn{1}{c|}{ Implementasi pada DPM Kema Tel-U } \\
\hline $\begin{array}{l}\text { Manajemen SDM berfungsi untuk } \\
\text { perencanaan kebutuhan SDM } \\
\text { (Priyono, 2010) }\end{array}$ & $\begin{array}{l}\text { Kebutuhan SDM direncanakan dari awal periode } \\
\text { kepengurusan, dengan memperhatikan tugas yang } \\
\text { akan diemban selama periode menjabat }\end{array}$ \\
\hline $\begin{array}{l}\text { Manajemen SDM berfungsi untuk } \\
\text { staffing sesuai kebutuhan organisasi } \\
\text { (Priyono, 2010) }\end{array}$ & $\begin{array}{l}\text { Rekrutmen terbuka dilakukan oleh DPM Kema } \\
\text { Tel-U untuk memenuhi kebutuhan kelengkapan } \\
\text { SDM organisasi }\end{array}$ \\
\hline $\begin{array}{l}\text { Manajemen SDM berfungsi untuk } \\
\text { penilaian kinerja (Priyono, 2010) }\end{array}$ & $\begin{array}{l}\text { Belum ada format penilaian kinerja yang baku } \\
\text { pada DPM Kema Tel-U }\end{array}$ \\
\hline $\begin{array}{l}\text { Manajemen SDM berfungsi untuk } \\
\text { perbaikan kualitas pekerja dan } \\
\text { lingkungan kerja (Priyono, 2010) }\end{array}$ & $\begin{array}{l}\text { Telah dilakukan pencerdasan internal yang } \\
\text { ditujukan kepada seluruh anggota DPM Kema } \\
\text { Tel-U, namun belum terlaksana secara optimal }\end{array}$ \\
\hline $\begin{array}{l}\text { Manajemen SDM berfungsi untuk } \\
\text { penerapan efektifitas hubungan } \\
\text { kerja (Priyono, 2010) }\end{array}$ & $\begin{array}{l}\text { Segala keputusan yang dicari akan diambil } \\
\text { berdasarkan sistem musyawarah anggota untuk } \\
\text { mencapai mufakat }\end{array}$ \\
\hline
\end{tabular}

Berdasarkan tabel 1 di atas, terlihat adanya permasalahan manajemen sumber daya manusia pada Dewan Perwakilan Mahasiswa Keluarga Mahasiswa Telkom University, yakni belum adanya format penilaian kinerja yang baku yang berakibat pada tidak optimalnya upaya untuk memperbaiki kualitas anggota dan lingkungan kerja dari DPM Kema Tel-U itu sendiri. Oleh sebab itu, dirumuskan pertanyaan penelitian "Apa saja indikator penilaian kinerja untuk memperbaiki kualitas anggota dan lingkungan kerja DPM Kema Tel-U?”.

Dalam penelitian ini, peneliti akan membahas mengenai pengaruh manajemen sumber daya manusia terhadap Dewan Perwakilan Mahasiswa Universitas Telkom. Harapannya, penelitian ini dapat menjadi sebuah landasan dalam bagaimana cara mengimplementasikan manajemen sumber daya yang baik dalam organisasi, khususnya pada organisasi mahasiswa yang bergerak di ranah legislatif.

\section{Studi Literatur}

\subsection{Manajemen}

Menurut Robbins \& Coulter (2012), manajemen merupakan aktivitas yang melibatkan koordinasi serta pengawasan kegiatan kerja orang lain, sehingga pekerjaan dapat diselesaikan secara efektif dan efisien oleh orangorang yang bertanggung-jawab untuk melakukannya. Aktivitas tersebut memiliki empat fungsi, di antaranya adalah planning atau perencanaan tujuan, lalu organizing atau melakukan penataan untuk mencapai tujuan, kemudian leading atau mengelola orang-orang yang akan melakukan pekerjaan tertentu, hingga controlling atau melakukan pengawasan serta evaluasi atas kegiatan yang telah dilakukan.

\subsection{Manajemen Sumber Daya Manusia}

Manajemen sumber daya manusia atau MSDM merupakan suatu alat manajerial berupa suatu proses atau kebijakan dalam organisasi untuk merencanakan, mengelola, dan mengendalikan sumber daya manusia yang 
dimiliki. MSDM memiliki beberapa fungsi penting dalam organisasi, seperti untuk perencanaan kebutuhan SDM, untuk staffing sesuai kebutuhan organisasi, untuk penilaian kinerja, perbaikan kualitas pekerja dan lingkungan kerja, serta untuk penerapan atas efektifitas hubungan kerja (Priyono, 2010). Adapun fungsi-fungsi MSDM dijabarkan pada tabel 2 di bawah ini.

Tabel 2. Penjabaran fungsi-fungsi MSDM

\begin{tabular}{|c|c|}
\hline Fungsi MSDM & Kegiatan yang Dilakukan \\
\hline \multirow{2}{*}{$\begin{array}{l}\text { Perencanaan kebutuhan } \\
\text { SDM }\end{array}$} & $\begin{array}{l}\text { Perencanaan dan peramalan permintaan anggota organisasi } \\
\text { dalam jangka pendek maupun panjang }\end{array}$ \\
\hline & $\begin{array}{l}\text { Analisis jabatan pada organisasi untuk menentukan kriteria } \\
\text { yang dibutuhkan }\end{array}$ \\
\hline \multirow{2}{*}{$\begin{array}{l}\text { Staffing sesuai kebutuhan } \\
\text { organisasi }\end{array}$} & Rekrutmen calon anggota organisasi \\
\hline & Seleksi calon yang dinilai paling memenuhi syarat \\
\hline \multirow{2}{*}{ Penilaian kinerja } & Penilaian dan pengevaluasian perilaku anggota organisasi \\
\hline & Analisis dan pemberian motivasi sesuai perilaku anggota \\
\hline \multirow{3}{*}{$\begin{array}{l}\text { Perbaikan kualitas } \\
\text { pekerja dan lingkungan } \\
\text { kerja }\end{array}$} & $\begin{array}{l}\text { Menentukan, merancang, serta mengimplementasikan } \\
\text { program pelatihan dan pengembangan SDM guna } \\
\text { meningkatkan kemampuan dan kinerja anggota organisasi }\end{array}$ \\
\hline & $\begin{array}{l}\text { Memperbaiki kualitas lingkungan organisasi, khususnya } \\
\text { melalui kualitas kehidupan berorganisasi dan program- } \\
\text { program perbaikan produktifitas }\end{array}$ \\
\hline & $\begin{array}{l}\text { Memperbaiki kondisi fisik kerja guna memaksimalkan } \\
\text { kesehatan dan keselamatan anggota organisasi }\end{array}$ \\
\hline \multirow{3}{*}{$\begin{array}{l}\text { Penerapan efektifitas } \\
\text { hubungan kerja }\end{array}$} & $\begin{array}{l}\text { Mengakui dan menaruh rasa hormat terhadap hak-hak } \\
\text { sesama anggota organisasi }\end{array}$ \\
\hline & $\begin{array}{l}\text { Melakukan tawar-menawar dan menetapkan prosedur } \\
\text { bagaimana keluhan anggota organisasi dapat disampaikan }\end{array}$ \\
\hline & Melakukan penelitian tentang kegiatan-kegiatan MSDM \\
\hline
\end{tabular}

Sumber: Olahan peneliti dari Priyono, 2010

\subsection{Perilaku Organisasi}

Tahir (2014) menyebutkan bahwa perilaku organisasi merupakan sebuah studi terkait aspek-aspek tingkah laku manusia dalam suatu organisasi maupun kelompok tertentu, meliputi aspek yang ditimbulkan dari pengaruh organisasi terhadap manusia ataupun manusia terhadap organisasi.

\subsection{Kinerja}

Moeheriono (2010) memaparkan bahwa kinerja merupakan hasil kerja yang dapat dicapai oleh seseorang atau sekelompok orang dalam suatu organisasi dalam upaya mewujudkan tujuan yang dituangkan melalui perencanaan strategis organisasi. Kinerja dapat diketahui dan diukur jika individu telah mempunyai kriteria atau tolok ukur yang ditetapkan oleh organisasi.

\section{Metode Penelitian}

\subsection{Populasi dan Sampel}

Penelitian ini ditujukan terhadap DPM Kema Tel-U dengan populasi 34 orang. Teknik sampling yang digunakan adalah purposive sampling atau memilih anggota sampel secara disengaja, karena sampel tersebut dapat mewakili 
dalam memberikan informasi yang dibutuhkan (Indrawati, 2015). Sedangkan untuk mengetahui jumlah sampel minimal pada penelitian ini, peneliti menggunakan rumus Slovin (Suharsaputra, 2012) sebagai berikut :

Keterangan :

$$
n=\frac{N}{1+N e^{2}}
$$

$\mathrm{n}=$ Jumlah sampel

$\mathrm{N}=$ Jumlah populasi

e $=$ Persentase toleransi kesalahan pengambilan sampel yang dapat diterima

Maka :

$$
n=\frac{34}{1+34(0.1)^{2}}=\frac{34}{1.34}=25.37
$$

Persentase toleransi kesalahan yang dapat diterima dalam penelitian ini adalah sebesar 10\%, dengan mempertimbangkan responden yang homogen. Dengan menggunakan rumus Slovin tersebut, sampel minimal dari penelitian ini adalah sebesar 25.37, atau dibulatkan menjadi 25 orang anggota DPM Kema Tel-U.

\subsection{Pengumpulan Data}

Data yang dibutuhkan dalam penelitian ini akan dikumpulkan melalui beberapa cara. Pertama, melalui metode focus group discussion atau FGD, yakni sebuah metode pengumpulan data pada penelitian kualitatif yang berfokus pada isu-isu spesifik dengan melibatkan sekelompok orang yang berpartisipasi dalam sebuah diskusi interaktif (Hennink, 2014).

Lalu melalui wawancara semi-terstruktur, yang pelaksanaannya lebih bebas dan mendalam sehingga peneliti dapat menemukan inti permasalahan secara lebih terbuka dengan mengembangkan pertanyaan dari pedoman wawancara yang telah dirumuskan sebelumnya (Satori \& Komariah, 2014).

Focus group discussion dan wawancara mendalam tersebut akan dilakukan dengan anggota-anggota DPM Kema Tel-U untuk mendapatkan data primer yang dibutuhkan. Terakhir, data sekunder akan didapat melalui studi pustaka terhadap buku dan sumber-sumber lainnya yang relevan dengan penelitian yang dilakukan.

\subsection{Teknik Analisis Data}

Penelitian ini dilakukan untuk mengetahui pengaruh manajemen sumber daya manusia terhadap Dewan Perwakilan Mahasiswa Universitas Telkom, dengan tahapan analisis seperti yang tergambarkan pada gambar 1.

Studi literatur terkait MSDM

Mendefinisikan indikator penilaian kinerja untuk memperbaiki kualitas anggota dan lingkungan kerja DPM Kema Tel-U
Mendefinisikan variabel MSDM berdasarkan studi literatur

Gambar 1. Tahapan penelitian

Studi literatur yang perlu dilakukan untuk memperkuat perspektif peneliti, dan berguna untuk menganalisis data menggunakan teori dari hasil-hasil penelitian terdahulu. Dengan demikian, peneliti dapat lebih memahami metode riset serta cara pengaplikasiannya, dan memahami pemikiran dan apa yang dilakukan oleh peneliti dalam bidang serupa (Soewardikoen, 2013). Peneliti akan mengidentifikasi beberapa indikator penilaian kinerja dan juga merumuskan pertanyaan wawancara, berdasarkan studi literatur yang telah dilakukan. 


\section{Hasil dan Pembahasan}

Berdasarkan studi literatur yang telah dilakukan, peneliti mengelompokkan indikator-indikator penilaian kinerja yang dijabarkan pada tabel 3 .

Tabel 3. Indikator penilaian kinerja berdasarkan studi literatur

\begin{tabular}{|c|c|c|c|c|c|}
\hline 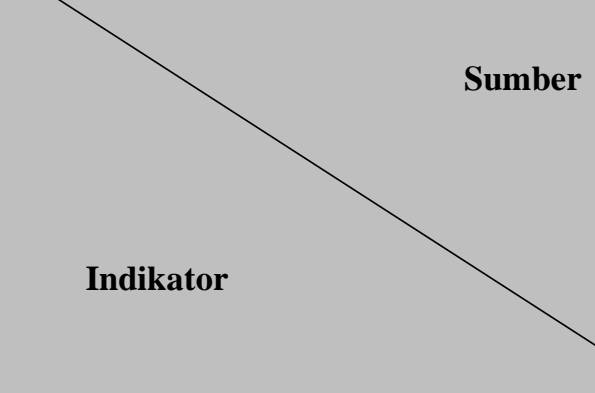 & 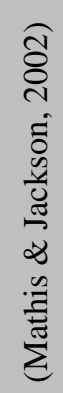 & 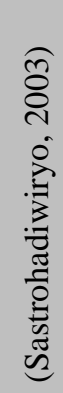 & 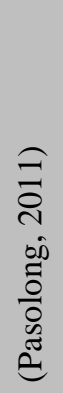 & 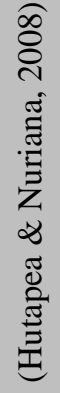 & 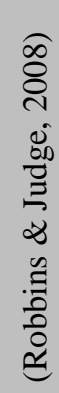 \\
\hline Jangka waktu output & $\checkmark$ & & $\checkmark$ & & $\checkmark$ \\
\hline Kehadiran di tempat kerja & $\checkmark$ & & & & \\
\hline Kejujuran & & $\checkmark$ & $\checkmark$ & & \\
\hline Kemampuan mengambil keputusan & & $\checkmark$ & & & \\
\hline Kemandirian & & & & & $\checkmark$ \\
\hline Kepemimpinan & & $\checkmark$ & & & \\
\hline Ketaatan & & $\checkmark$ & $\checkmark$ & & \\
\hline Keterampilan & & & & $\checkmark$ & $\checkmark$ \\
\hline Kualitas output & $\checkmark$ & $\checkmark$ & $\checkmark$ & & $\checkmark$ \\
\hline Kuantitas output & $\checkmark$ & $\checkmark$ & $\checkmark$ & & $\checkmark$ \\
\hline Loyalitas & & $\checkmark$ & & & $\checkmark$ \\
\hline Memiliki tujuan dalam bekerja & & & $\checkmark$ & & \\
\hline Pengetahuan & & & & $\checkmark$ & \\
\hline Responsif dalam mengenali kebutuhan & & & $\checkmark$ & & \\
\hline Sikap kooperatif & $\checkmark$ & $\checkmark$ & $\checkmark$ & $\checkmark$ & \\
\hline Tanggung jawab & & $\checkmark$ & & & \\
\hline
\end{tabular}

Dari hasil studi literatur, didapat beberapa kesamaan tertinggi yakni pada indikator kualitas output, kuantitas output, serta sikap kooperatif anggota, dan diikuti dengan indikator jangka waktu output. Indikator-indikator yang telah didapat kemudian ditanyakan kepada 28 responden yang merupakan anggota aktif DPM Kema Tel-U, yang terdiri dari satu orang pimpinan, delapan orang koordinator badan dan komisi, serta 19 orang anggota dewan. Responden tersebut dimintai keterangan melalui FGD maupun wawancara mendalam, didapat hasil seperti yang terlihat pada tabel 4 .

Tabel 4. Indikator penilaian kinerja berdasarkan FGD dan wawancara

\begin{tabular}{|l|c|}
\hline \multicolumn{1}{|c|}{ Indikator } & Persentase \\
\hline Ketepatan waktu dalam mengerjakan tugas pada organisasi & $100 \%$ \\
\hline Kehadiran pada setiap agenda kegiatan DPM Kema Tel-U & $96.4 \%$ \\
\hline Kejujuran antar sesama anggota DPM Kema Tel-U & $85.7 \%$ \\
\hline Kemampuan mengambil keputusan & $100 \%$ \\
\hline Kemandirian dalam menjalankan tugas pada organisasi & $75 \%$ \\
\hline Sikap kepemimpinan dalam berorganisasi & $96.4 \%$ \\
\hline
\end{tabular}




\begin{tabular}{|l|c|}
\hline Ketaatan terhadap aturan yang telah disepakati bersama & $96.4 \%$ \\
\hline Keterampilan dalam menjalankan tugas anggota DPM Kema Tel-U & $96.4 \%$ \\
\hline Kualitas dalam berkontribusi pada setiap kegiatan DPM Kema Tel-U & $89.3 \%$ \\
\hline Jumlah kontribusi pada setiap kegiatan DPM Kema Tel-U & $96.4 \%$ \\
\hline Tingkat loyalitas terhadap DPM Kema Tel-U & $85.7 \%$ \\
\hline Memiliki tujuan dalam menjadi anggota DPM Kema Tel-U & $89.3 \%$ \\
\hline Pengetahuan terkait pengawasan, legislasi, aspirasi, serta anggaran & $85.7 \%$ \\
\hline Responsif dalam mengenali kebutuhan mahasiswa & $96.4 \%$ \\
\hline Sikap kooperatif antar sesama anggota DPM Kema Tel-U & $92.9 \%$ \\
\hline Tanggung jawab terhadap tugas sebagai anggota DPM Kema Tel-U & $100 \%$ \\
\hline
\end{tabular}

\section{Kesimpulan}

Berdasarkan penelitian yang telah dilakukan, didapat beberapa variabel yang dapat dijadikan indikator penilaian kinerja untuk memperbaiki kualitas anggota dan lingkungan kerja DPM Kema Tel-U. Hasil dari penelitian ini mengusulkan 16 indikator penilaian kinerja Dewan Perwakilan Mahasiswa Universitas Telkom, seperti yang tergambarkan pada tabel 5 .

Tabel 5. Indikator penilaian kinerja anggota DPM Kema Tel-U

\begin{tabular}{|r|l|}
\hline \multicolumn{1}{|c|}{ No. } & \multicolumn{1}{|c|}{ Indikator Penilaian Kinerja Anggota DPM Kema Tel-U } \\
\hline 1 & Ketepatan waktu dalam mengerjakan tugas organisasi \\
\hline 2 & Kehadiran pada setiap agenda kegiatan DPM Kema Tel-U \\
\hline 3 & Kejujuran antar sesama anggota DPM Kema Tel-U \\
\hline 4 & Kemampuan mengambil keputusan \\
\hline 5 & Kemandirian dalam menjalankan tugas pada organisasi \\
\hline 6 & Sikap kepemimpinan dalam berorganisasi \\
\hline 7 & Ketaatan terhadap aturan yang telah disepakati bersama \\
\hline 8 & Keterampilan dalam menjalankan tugas anggota DPM Kema Tel-U \\
\hline 9 & Kualitas dalam berkontribusi pada setiap kegiatan DPM Kema Tel-U \\
\hline 10 & Jumlah kontribusi pada setiap kegiatan DPM Kema Tel-U \\
\hline 11 & Tingkat loyalitas terhadap DPM Kema Tel-U \\
\hline 12 & Memiliki tujuan dalam menjadi anggota DPM Kema Tel-U \\
\hline 13 & Pengetahuan terkait pengawasan, legislasi, aspirasi, serta anggaran \\
\hline 14 & Responsif dalam mengenali kebutuhan mahasiswa \\
\hline 15 & Sikap kooperatif terhadap anggota DPM Kema Tel-U yang lain \\
\hline 16 & Tanggung jawab terhadap tugas sebagai anggota DPM Kema Tel-U \\
\hline
\end{tabular}

\section{Saran Pengembangan}

Penelitian ini dapat dikembangkan kembali untuk keperluan praktis maupun akademis. Indikator yang diusulkan dapat mempermudah pengukuran tingkat kinerja dari anggota Dewan Perwakilan Mahasiswa Universitas Telkom, sehingga organisasi dapat mengetahui hal apa yang harus dibenahi agar dapat meningkatkan kinerja dari anggota DPM Kema Tel-U.

\section{Ucapan Terima Kasih}

Terima kasih yang sebesar-besarnya saya ucapkan kepada seluruh pihak, khususnya Dewan Perwakilan Mahasiswa Universitas Telkom yang telah membantu dalam terealisasinya penelitian ini. 


\section{Daftar Pustaka}

Hennink, M. M. (2014). Focus Group Discussions : Understanding Qualitative Research. New York: Oxford University Press.

Hutapea, P., \& Nuriana, T. (2008). Kompetensi Plus: Teori, Desain, Kasus, dan Penerapan untuk HR dan Organisasi yang Dinamis. Jakarta: PT Gramedia Pustaka Utama.

Indrawati. (2015). Metode Penelitian Manajemen dan Bisnis : Konvergensi Teknologi Komunikasi dan Informasi. Bandung: Refika Aditama.

Mathis, R. L., \& Jackson, J. H. (2002). Manajemen Sumber Daya Manusia. Jakarta: Salemba Empat.

Moeheriono. (2010). Pengukuran Kinerja Berbasis Kompetensi (2 ed.). Jakarta: Ghalia Indonesia.

Pasolong, H. (2011). Teori Administrasi Publik. Bandung: Alfabeta.

Priyono. (2010). Manajemen Sumber Daya Manusia. Sidoarjo: Zifatama Publisher.

Robbins, S. P., \& Coulter, M. (2012). Management (11 ed.). New Jersey: Pearson Education Limited.

Robbins, S. P., \& Judge, T. A. (2008). Perilaku Organisasi (12 ed.). Jakarta: Salemba Empat.

Sastrohadiwiryo, B. S. (2003). Manajemen Tenaga Kerja Indonesia (2 ed.). Jakarta: Bumi Aksara.

Satori, D., \& Komariah, A. (2014). Metodologi Penelitian Kualitatif. Bandung: Alfabeta.

Soewardikoen, D. W. (2013). Metodologi Penelitian Visual, dari Seminar ke Tugas Akhir. Bandung: Dinamika Komunika.

Suharsaputra, U. (2012). Metode Penelitian Kuantitatif, Kualitatif, dan Tindakan. Bandung: PT Revika Aditama. Tahir, A. (2014). Buku Ajar Perilaku Organisasi. Yogyakarta: Deepublish. 